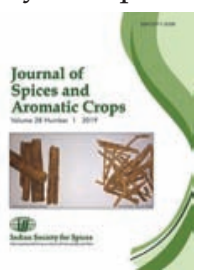

\title{
Development of a real-time PCR based protocol for quantifying Radopholus similis in field samples
}

\author{
P B Krishna ${ }^{1} \&$ S J Eapen* \\ ICAR-Indian Institute of Spices Research, Kozhikode-673 012, Kerala. \\ *E-mail: Santhosh.Eapen@icar.gov.in
}

Received 09 May 2019; Revised 04 June 2019; Accepted 24 June 2019

\begin{abstract}
The burrowing nematode, Radopholus similis, is an obligate migratory endoparasite. Currently detection of this nematode is carried out mostly by physically extracting them from soil and then observing under a light microscope. To identify this nematode, a thorough knowledge about their morphological features is quite indispensable. Developing a DNA based detection technique makes it more convenient and accurate in detection. Though PCR based methods have been reported by earlier workers, developing a real-time PCR based method will enable estimating their population in field samples. In this study, real-time PCR primers were designed using the DNA sequences from the ITS region of

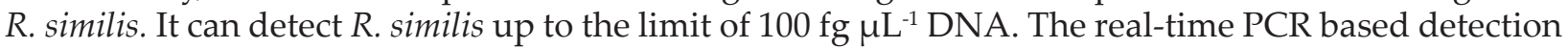
serves as an efficient tool for the detection and estimation of this nematode from soil samples.
\end{abstract}

Keywords: burrowing nematode, diagnostics, ITS, Radopholus similis, real-time PCR, SYBR green

\section{Introduction}

The burrowing nematode, Radopholus similis (Cobb 1893; Thorne 1949) is an obligate migratory plant parasitic nematode, which is endoparasitic in nature. It is a highly polyphagous plant parasitic nematode and found to infect about 365 plant species including banana, black pepper, several palms and indoor decorative plants (Holdeman 1986). It enters and feeds in the cortex of the roots. This nematode occurs in tropical and subtropical areas around the world, and is seen mainly in Australia, Asia,
Africa, and South America. R. similis is one of the ten most damaging nematodes in the world. More than 30 species are reported in the genus Radopholus. Out of these only R. similis is reported to be of economic significance. Slow decline disease of pepper, caused by $R$. similis, is a major problem for pepper cultivation (Thorne 1961). In black pepper it shows symptoms like yellowing of leaves, defoliation, necrotic lesions on the root leading to loss in productivity and slow death of the vine. It accounts for low productivity of black pepper in India. 
The damage to crops caused by plant-parasitic nematodes is related to their population densities in soil at sowing time and their reproduction potential. The management of the nematode largely depends on its early detection. Accurate identification of the nematode species is relevant for their effective management. The morphological and morphometric features allow classifying nematodes within their respective genus. The major advantage of this approach is that it is almost costless, but the drawback lies in the need for substantial expertise and training. It is very difficult to identify the species of nematodes as they are microscopic in size, similar in morphology and have very few distinguishable taxonomic characters.

PCR based molecular methods may overcome the drawbacks of traditional identification methods. Developing DNA based detection technique makes it more convenient and accurate in detecting the pathogen. Molecular based detection techniques like the conventional PCR were done on Meloidogyne, Heterodera and Globodera (Zijlstra 2000; Subbotin et al. 1999 \& 2000). Though loopmediated isothermal amplification (LAMP) and several PCR assays were developed for detection of R. similis (Ge et al. 2007; Wang et al. 2011; Aravind et al. 2011; Peng et al. 2012), they are not suitable for quantifying the nematodes in soil and plant samples.

Real-time PCR, although more expensive than conventional PCR, have the advantages of speed and sensitivity. In addition, this method provides quantitative information regarding the approximate number of nematodes present in the sample. Quantitative PCR assays have been designed for the plant-parasitic nematode genera Bursaphelenchus (Wang et al. 2005), Meloidogyne (Toyota et al. 2008), Globodera (Toyota et al. 2008; Madani et al. 2005), Heterodera (Goto et al. 2009), Pratylenchus (Berry et al. 2008; Sato et al. 2007) and Xiphinema (Berry et al. 2008). Here we describe the development of a real time PCR based detection tool for $R$. similis isolated from black pepper cropping system.

\section{Materials and methods}

\section{Isolation of nematodes}

The rhizosphere soil and root samples of black pepper vines showing symptoms of slow decline disease, like yellowing, stunted growth and black lesions on the root were collected from ten different locations of Kerala and Karnataka states of India. The samples were processed using the protocol described by Cobb and the identity of genus Radopholus was confirmed microscopically. The isolated nematodes were surface sterilized and cultured on carrot discs (Reise et al. 1987). Nematodes from these cultures were used for further studies.

\section{Amplification, cloning and sequencing of ITS region}

Molecular characterization of the ten isolates of nematodes was done by PCR amplification and sequencing of the internal transcribed spacer(ITS) region, using the primer pair, ITS-F (5" TTGATTACGTCCCTGCCCTTT -3") and ITS-R (5" - TTTCACTCGCCGTTACTAAGG -3"), based on the 18S rDNA and 26S rDNA sequences (Vrain et al. 1992). The DNA was extracted from the isolates using the protocol mentioned by Emmons et al. (1979). PCR amplification of the DNA was done using the amplification profile consisting of $5 \mathrm{~min}$ at $94^{\circ} \mathrm{C} ; 34$ cycles of $30 \mathrm{sec}$ at $94{ }^{\circ} \mathrm{C}, 1 \mathrm{~min}$ at $62{ }^{\circ} \mathrm{C}$, and $1 \mathrm{~min}$ at $72{ }^{\circ} \mathrm{C}$; and a final $10 \mathrm{~min}$ extension at $72{ }^{\circ} \mathrm{C}$. Standard protocols were used for purifying the amplified fragments from the agarose gel by using Thermo Scientific Gene JET Gel Extraction Kit (Thermo Fisher Scientific Inc. MA USA). Eluted PCR products were cloned into $\mathrm{pTZ}$ T7R/T vector (Thermo Scientific). Freshly prepared competent cells of Escherichia coli DH5 $\alpha$ were transformed with recombinant plasmids and positive clones were selected and grown in LB medium. Plasmids were isolated and sequenced at M/s Eurofins Genomics India Pvt. Ltd., Bengaluru, India. The forward and reverse sequences obtained after sequencing were assembled using MEGA software (Kumar et al. 2016). The vector contamination in the assembled sequences was removed by using NCBI VecScreen. The sequences were edited using BioEdit version 7.2.5 (Hall 1999). A homology search of each sequence in FASTA format was done using BLAST-N programme (Altschul et al. 1997), to identify the closely related sequences from the GenBank database. All the sequences were submitted in NCBI. 


\section{Designing and optimization of real-time $P C R$ primers}

The primer set (RAD-F:AGACTTGATGAGCGCAGA and RAD-R: CGTGCCAGAGGAAGTGA) was designed from the ITS sequences obtained from the ten $R$. similis isolates. BLAST searches were used to compare the primers with other sequences in the public database to confirm the specificity of the primers. The primers were designed using the Primer 3+ software (Untergasser et al. 2007).

\section{Standard graph for the real-time PCR based detection}

DNA of the isolate RS01 was isolated from 2000 nematodes using phenol: chloroform (24:1) extraction method. Using this DNA sample as template, real-time PCR was done along with water and the DNA of Meloidogyne sp. and Steinernema sp. as negative controls using a qPCR thermocycler (Qiagen), Quantifast SYBR green $2 \mathrm{x}$ master mix (Qiagen) and $0.25 \mu \mathrm{M}$ primer. The real time PCR profile used in the reaction for the above primer was: $95^{\circ} \mathrm{C}$ for $10 \mathrm{~min}$ followed by 40 cycles of $95^{\circ} \mathrm{C}$ for $10 \mathrm{sec}, 60^{\circ} \mathrm{C}$ annealing for $45 \mathrm{sec}$ and a melt at $50-99{ }^{\circ} \mathrm{C}$. All assays were repeated three times. A standard graph for the detection of $R$. similis was thus obtained.

Correlating $C t$ value to the number of $\mathrm{R}$. similis

R. similis was grouped into sets of $1,5,10,50$, and 500 and DNA was extracted from each set. While extracting DNA from a single nematode or a set of very few nematodes, it was placed in a drop of extraction buffer placed on clean microscopic glass slide. Each nematode set mentioned above was cut into several pieces under a microscope. The nematode sample was then transferred into a small vial and DNA was extracted using the phenol: chloroform (24:1) extraction method described by Emmons et al. (1979). Real-time PCR was carried out using these DNA samples and the Ct values obtained were plotted on the standard graph previously created for the serial dilutions of nematode DNA obtained from 2000 nematodes. An approximate measure for the concentration and $\mathrm{Ct}$ values corresponding to the DNA samples extracted from a fixed number of $R$. similis was thus obtained. These values will be helpful in predicting the number of nematodes that is present in a sample with a particular $\mathrm{Ct}$ value.
Validation of real-time PCR based detection using field sample

In order to validate the real-time PCR method developed for the detection of $R$. similis, 30 soil samples from black pepper rhizosphere were collected from different regions of Kerala. To examine the reliability of the method, especially to detect the nematode in symptomless plants, samples were taken from apparently healthy plants around the infected plants. About $100 \mathrm{~g}$ of field soil sample was taken uniformly from each of the sample sites and the nematodes were extracted from the soil by Cobb's sieving and decanting method. The nematode suspension so obtained was subjected to microscopic observations. After quantifying the $R$. similis by direct microscopic examination, all the nematodes present in each sample was pelleted in Eppendorf tubes by centrifugation, the DNA was extracted and a qPCR assay was conducted by adopting the corresponding standardized protocols. The specificity of the qPCR product was also checked by subjecting to melt curve analysis from $60{ }^{\circ} \mathrm{C}$ to $95{ }^{\circ} \mathrm{C}$. The $\mathrm{Ct}$ values of the reactions were calculated using the Rotor-Gene Q system software and the corresponding number of nematodes was calculated using the standard curve. A correlation analysis was conducted from the number of nematodes obtained using microscopic method and the values obtained from real time PCR based method using the software SAS 9.3.

\section{Results and discussion}

Accurate identification and quantification of plant parasitic nematodes are critical for making any plant management decision. However, the currently available traditional methods of diagnostic assays are not ideal as they are time consuming and require expertise in nematode identification. The conventional PCR-based detection methods and LAMP method for detection of $R$. similis do not provide any information about their population level in soil.

Several studies have clearly demonstrated that real-time PCR assays are well suited for detection, identification and even quantification of plantparasitic nematodes. Real-time PCR assays have been developed for the root-knot nematodes Meloidogyne javanica (Berry et al. 2008), M. chitwoodi 
and M. fallax (Zijlstra \& Van Hoof 2006), M. minor (De Weerd t et al. 2011). They have been developed for the lesion nematodes Pratylenchus zeae (Berry et al. 2008), P. thornei (Yan et al. 2012), P. scribneri (Huang \& Yan 2017), and for P. penetrans (Mokrini et al. 2013); for species specific identification and differentiation of Ditylenchus dipsaci, D. destructor, and D. gigas (Jeszkeet al. 2015), for the identification of the dagger nematode Xiphinema elongatus (Berry et al. 2008), as well as X. index, X. diversicaudatum, X. vuittenezi, X. italiae (Van Ghelder et al. 2015). Real-time PCR assays have also been developed for species level identification of cyst nematodes of the genus Globodera and Heterodera (Gamel et al. 2017; Madani et al. 2005 \& 2011), for the reniform nematode Rotylenchus reniformis (Sayler et al. 2012) and the pinewood nematode Bursaphelenchus xylophilus (François et al. 2007). So it was felt that a qPCR assay is a potentially useful alternative to the current molecular tools as it provides quantitative information about the nematode.

DNA isolation, PCR amplification and sequencing of ITS region

For developing a qPCR protocol for $R$. similis, ten different isolates of $R$. similis were obtained from infected black pepper soils in Kerala and Karnataka. DNA from these isolates was extracted using phenol: chloroform (24:1) extraction method and then the ITS region of each of these DNA was amplified and sequenced.
PCR amplification of ten isolates of $R$. similis DNA using the universal primers of the rDNA-ITS region generated approximately $920 \mathrm{bp}$ long products. These sequences showed similarity to the ITS regions of $R$. similis isolates reported worldwide. Nucleotide sequences of PCR products from these ten isolates were deposited in NCBI (Table 1).

\section{Primer designing and quantitative real-time PCR}

A species-specific real-time PCR primer pair ( $\operatorname{Rad}$ $F$ and Rad R) was designed using these sequences to specifically amplify a 227 bp product. It showed similarity to all the $R$. similis nematode ITS sequences deposited in GenBank. Real-time PCR analysis was carried out with the DNA isolated from $R$. similis along with water and negative control. The primers specifically amplified $R$. similis DNA (Fig. 1). A standard curve was generated using DNA isolated from $2000 \mathrm{R}$. similis and serially diluted with water in a 1:1 dilution series (Fig. 2). This standard curve would later help in identifying the approximate concentration of $R$. similis nematode(s) in any unknown sample based on the cycle threshold (Ct) value of that sample. The Ct values were correlated with the DNA template concentration $\left(R^{2}=0.996\right)$, indicating the validity of the assay and its potential for quantification of target DNA (Table 2). The potential of the RT-qPCR technique in detection of the number of nematodes present in a sample was determined. This data provided

Table 1. Details of GenBank accession numbers for the ITS sequences of the ten isolates of $R$. similis

\begin{tabular}{llll}
\hline Isolate No. & Location & Host plant & GenBank Accn. No. \\
\hline IISR_RS01 & Kozhikode, Kerala & Black pepper & MF197883 \\
IISR_RS02 & Idukki, Kerala & Black pepper & MF197884 \\
IISR_RS03 & Kozhikode, Kerala & Banana & MF197885 \\
IISR_RS04 & Malappuram, Kerala & Banana & MF197886 \\
IISR_RS05 & Sirsi, Karnataka & Black pepper & MF197887 \\
IISR_RS06 & Wayanad, Kerala & Black pepper & MF197888 \\
IISR_RS07 & Malappuram, Kerala & Black pepper & MF197889 \\
IISR_Rs08 & Thiruvananthapuram, Kerala & Black pepper & MF197890 \\
IISR_RS09 & Thrissur, Kerala & Black pepper & MF197891 \\
IISR_RS10 & Kozhikode, Kerala & Black pepper & MF197892 \\
\hline
\end{tabular}



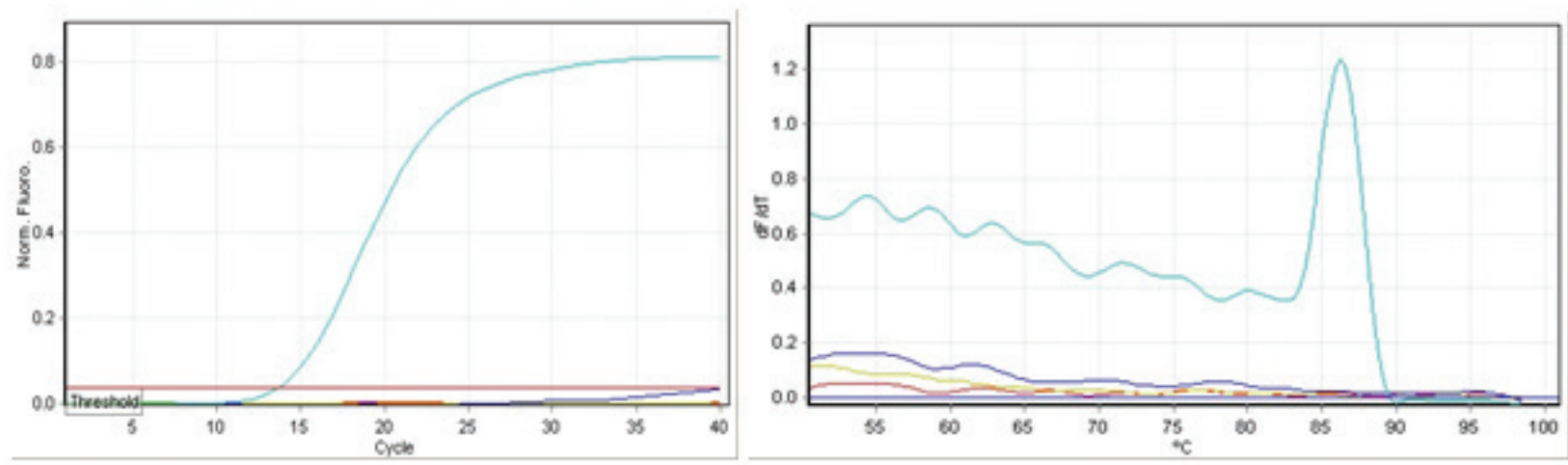

Fig. 1. Real-time PCR detection of $R$. similis (A) Amplification curves of real-time PCR obtained with positive, negative and water control; (B) Melt curve analysis of real-time PCR product
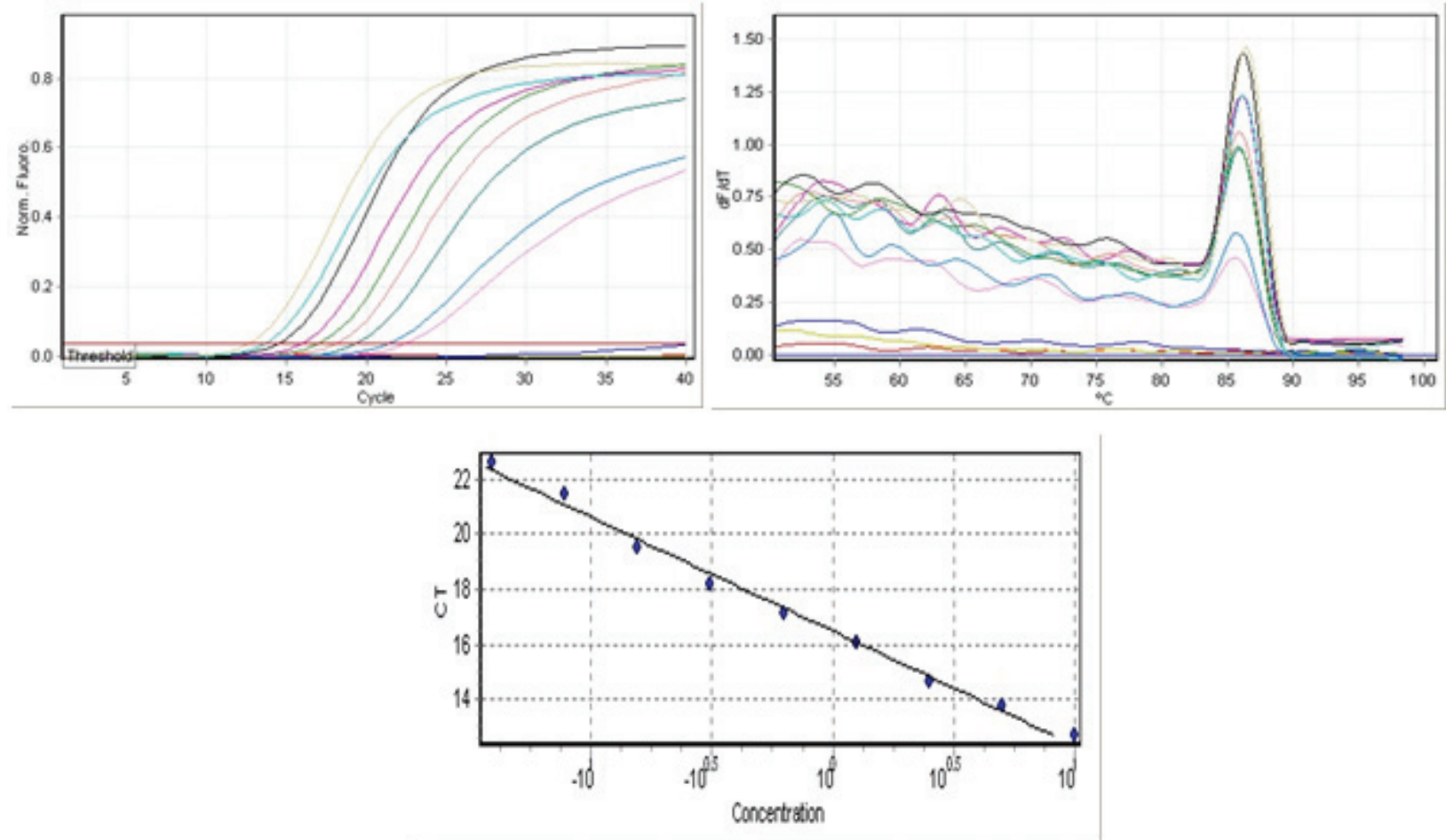

Fig. 2. Standard curve of real-time PCR obtained with a 1:1 dilution series of $R$. similis DNA: (A) Amplification curve, (B) Melt curve analysis and (C) Standard graph

the information regarding the approximate number of $R$. similis present in any test sample based on their $\mathrm{Ct}$ value. The DNA from nematodes ranging from 1-500 was correlated to Ct values (Table 3). The PCR assay also detected DNA from a single nematode of $R$. similis, which was $0.003 \mathrm{ng} \mu \mathrm{L}^{-1}$. Further, on 1:10 dilution of the DNA isolated from single nematode, the $\mathrm{Ct}$ values obtained were 29.30 and 31.93, respectively. The target DNA was detectable in suspensions diluted in water containing as little as $100 \mathrm{fg}$ of $R$. similis DNA.

R. similis was quantified directly in DNA extracts from its pure culture using a species specific qPCR. The assay was sensitive and detected $10^{-2}$ dilution of genomic DNA of a single juvenile nematode. The sensitivity of our $R$. similis assay was comparable with that observed from other qPCR assays. Wang et al. (2011) reported a PCR assay for detection of $R$. similis ITS-rDNA equivalent to $4 \times 10^{-3}$ nematodes. Madani et al. (2005) was able to detect a single second-stage juvenile of the cyst-forming nematodes Globodera pallida and $H$. schachtii using qPCR with SYBR Green I dye. Sato et al. (2007) could detect a single P. penetrans individual in a sample with abundant number of free-living nematodes using qPCR. 
Table 2. Ct value vs. DNA concentration obtained using real-time PCR with a 1:1 dilution series of $R$. similis DNA

\begin{tabular}{lll}
\hline Sample & Ct value & DNA concentration $\left(\mathrm{ng} \mu \mathrm{L}^{-1}\right)$ \\
\hline No template control (Water) & - & - \\
Negative control (DNA of Meloidogyne sp.) & - & - \\
Negative control (DNA of Steinernema sp.) & - & - \\
Sample 1 (DNA isolated from 2000 R. similis) & 12.71 & 8.266 \\
Sample 2 (1:2 dilution of sample 1) & 13.74 & 4.655 \\
Sample 3 (1:2 dilution of sample 2) & 14.62 & 2.823 \\
Sample 4 (1:2 dilution of sample 3) & 16.04 & 1.2812 \\
5 Sample 5 (1:2 dilution of sample 4) & 17.13 & 0.6979 \\
6 Sample 6 (1:2 dilution of sample 5) & 18.22 & 0.3795 \\
7 Sample 7 (1:2 dilution of sample 6) & 19.49 & 0.1854 \\
8 Sample 8 (1:2 dilution of sample 7) & 21.41 & 0.0642 \\
9 Sample 9 (1:2 dilution of sample 8) & 22.58 & 0.03314 \\
\hline
\end{tabular}

Table 3. Ct value Vs Concentration of DNA obtained using real-time PCR with different numbers of $R$. similis

\begin{tabular}{lll}
\hline $\begin{array}{l}\text { Number of } \\
\text { nematodes }\end{array}$ & $\begin{array}{l}\mathrm{Ct} \\
\text { nematodes }\end{array}$ & $\begin{array}{l}\text { Concentration } \\
\left(\mathrm{ng} \mu \mathrm{L}^{-1}\right)\end{array}$ \\
\hline 500 & 18.05 & 0.41 \\
50 & 20.59 & 0.10 \\
10 & 21.73 & 0.05 \\
5 & 24.39 & 0.01 \\
1 & 26.75 & 0.003 \\
\hline
\end{tabular}

Toyota et al. (2008) sensitively detected a single second-stage juvenile of $G$. rostochiensis in mixed nematode communities of 1,000 free-living individuals. Yan et al. (2012) developed a qPCR assay for $P$. thornei and detected one second-stage juvenile in $1 \mathrm{~g}$ of sterilized soil.

Validation of the real-time PCR based detection using field sample

The real-time PCR method developed for detection of $R$. similis in infected black pepper rhizosphere soil was validated using 30 field samples collected from different regions of Kerala. Among the 30 samples collected, 15 vines showed typical yellowing and 15 vines appeared to be uninfected with R. similis. However, when these soil samples were processed for nematode extraction and were subjected to direct microscopic count, a few samples taken from vines showing yellowing symptoms did not show the presence of $R$. similis and a few vines which appeared to be healthy were infected by the nematode. Further, the DNA from these samples was subjected to qPCR and the number of nematodes in each sample was estimated based on the $\mathrm{Ct}$ value obtained. The details are given in Table 4 . In the correlation analysis conducted using the number of nematodes obtained using microscopic method and the estimated population obtained from the real-time PCR based method, a positive correlation was observed (correlation coefficient $=0.94$ at $\mathrm{P}<0.01$ ). However, few samples which did not show the presence of any $R$. similis when observed microscopically showed a $\mathrm{Ct}$ value which corresponds to 1:100 dilution of a single R. similis DNA. This could be due to the presence of one by hundredth fraction of a degraded nematode, which was present in the soil and escaped through the pores of the sieve during nematode extraction process.

In this study, we developed a qPCR assay for $R$. similis based on the ITS region. The technique 
Table 4. Field validation of real-time PCR protocol for estimating burrowing nematodes

\begin{tabular}{|c|c|c|c|c|}
\hline \multirow[t]{2}{*}{ Location } & \multirow{2}{*}{$\begin{array}{l}\text { Yellowing and } \\
\text { wilting }\end{array}$} & \multirow{2}{*}{$\begin{array}{c}\text { No. of } R \text {. similis } \\
\text { observed through } \\
\text { sieving and counting }\end{array}$} & \multicolumn{2}{|c|}{ Real-time PCR } \\
\hline & & & Ct value & $\begin{array}{l}\text { Estimated range of } \\
R \text {. similis population }\end{array}$ \\
\hline Kozhikode & + & 3 & 25.02 & $1-5$ \\
\hline Kozhikode & + & 1 & 27.14 & $0-1$ \\
\hline Kozhikode & + & 5 & 24.03 & $5-10$ \\
\hline Palakkad & + & 9 & 22.59 & $5-10$ \\
\hline Malappuram & + & 0 & 31.42 & $0-1$ \\
\hline Palakkad & + & 9 & 22.53 & $5-10$ \\
\hline Kozhikode & + & 1 & 26.99 & $0-1$ \\
\hline Malappuram & + & 0 & 29.69 & $0-1$ \\
\hline Kozhikode & + & 0 & 29.99 & $0-1$ \\
\hline Palakkad & + & 8 & 23.11 & $5-10$ \\
\hline Kozhikode & + & 2 & 26.32 & $1-5$ \\
\hline Palakkad & + & 4 & 24.70 & $1-5$ \\
\hline Malappuram & + & 5 & 24.56 & $1-5$ \\
\hline Palakkad & + & 4 & 25.32 & $1-5$ \\
\hline Palakkad & + & 0 & 30.40 & $0-1$ \\
\hline Kozhikode & - & 0 & 30.27 & $0-1$ \\
\hline Kozhikode & - & 0 & 28.48 & $0-1$ \\
\hline Malappuram & - & 1 & 27.02 & $0-1$ \\
\hline Malappuram & - & 6 & 23.58 & $5-10$ \\
\hline Palakkad & - & 4 & 25.27 & $1-5$ \\
\hline Malappuram & - & 0 & 33.30 & 0 \\
\hline Malappuram & - & 0 & - & 0 \\
\hline Palakkad & - & 0 & 35.77 & 0 \\
\hline Palakkad & - & 0 & 34.15 & 0 \\
\hline Malappuram & - & 0 & 31.98 & 0 \\
\hline Malappuram & - & 0 & 32.80 & 0 \\
\hline Kozhikode & - & 0 & 31.77 & $0-1$ \\
\hline Kozhikode & - & 0 & 32.60 & 0 \\
\hline Palakkad & - & 0 & 31.28 & $0-1$ \\
\hline Malappuram & - & 0 & 31.69 & $0-1$ \\
\hline
\end{tabular}


developed could be effectively used for the detection of $R$. similis from field samples.

\section{Acknowledgments}

The authors are thankful to Director, ICARIndian Institute of Spices Research for facilitating the studies. The Indian Council of Agricultural Research funded this research under the outreach project titled "Phytophthora, Fusarium and Ralstonia diseases of horticultural and field crops."

\section{References}

Altschul S F, Madden T L, Schäffer A A, Zhang J, Zhang Z., Miller W \& Lipman D J 1997 Gapped BLAST and PSI-BLAST: a new generation of protein database search programs. Nucleic Acids Res. 25: 3389-3402.

Aravind R, Kumar A, Dinu A \& Eapen SJ 2011 Single tube duplex PCR for simultaneous detection of Phytophthora capsici and Radopholus similis infecting black pepper (Piper nigrum). Indian Phytopath. 64: 353-357.

Berry S D, Fargette M, Spaull V W, Morand S \& Cadet P 2008 Detection and quantification of rootknot nematode (Meloidogyne javanica), lesion nematode (Pratylenchus zeae) and dagger nematode (Xiphinemae longatum) parasites of sugarcane using real-time PCR. Mol. Cell Probe 22: 168-176.

De Weerdt M, Kox L, Waeyenberge L, Viaene N, \& Zijlstra C 2011 A real-time PCR assay to identify Meloidogyne minor. J. Phytopathol. 159: $80-84$.

Emmons S W, Klass M R, \& Hirsh D 1979 Analysis of the constancy of DNA sequences during development and evolution of the nematode Caenorhabditis elegans. Proc. National Acad. Sci. 76: 1333-1337.

François C, Castagnone C, Boonham N, Tomlinson J, Lawson R, Hockland S, Quill J, Vieira P, Mota M \& Castagnone-Sereno P 2007 Satellite DNA as a target for TaqMan real-time PCR detection of the pinewood nematode, Bursaphelenchus xylophilus. Mol. Plant Pathol. 8: 803-809.

Gamel S, Letort A, Fouville D, Folcher L \& Grenier E 2017Development and validation of real-time PCR assays based on novel molecular markers for the simultaneous detection and identification of Globodera pallida, G. rostochiensis and Heteroderas chachtii. Nematol. 19 :789-804.
Ge J J, Co A X, Zhou G L, Zhou G Z \& Xie B Y 2007 Development of duplex PCR assay for detection of burrowing nematode, Radopholus similis. Acta Phytopathol. Sin. 37: 472-478.

Goto K, Sato E \& Toyota K 2009 A novel detection method for the soybean cyst nematode Heterodera glycines Ichinohe using soil compaction and real-time PCR. Japanese J. Nematol. 39: 1-7.

Hall T A 1999 BioEdit: a user-friendly biological sequence alignment editor and analysis program for Windows 95/98/NT. In: Nucleic Acids Symposium Series (Vol. 41, No. 41, pp.95-98). [London]: Information Retrieval Ltd., c1979-c2000.

Holdeman Q L 1986 The burrowing nematode Radopholus similis sensu lato. Sacramento, CA: Nematology Publ., Calif. Dep. Food Agri., Div. of Plant Ind., 52pp.

Huang D \& Yan G 2017 Specific detection of the rootlesion nematode Pratylenchus scribneri using conventional and real-time PCR. Plant Dis. 101: 359-365.

Jeszke A, Dobosz R \& Obrepalska-Steplowska A 2015 A fast and sensitive method for the simultaneous identification of three important nematode species of the genus Ditylenchus. Pest Manag. Sci. 71: 243-249.

Kiewnick S, Frey J-E \& Braun-Kiewnick A 2015 Development and validation of LNA-based quantitative real-time PCR assays for detection and identification of the root-knot nematode Meloidogyne enterolobii in complex DNA backgrounds. Phytopathol. 105: 12451249.

Kumar S, Stecher G \& Tamura K 2016 MEGA7: molecular evolutionary genetics analysis version 7.0 for bigger datasets. Mol. Biol. Evol. 33: 1870-1874.

Madani M, Subbotin S A \& Moens M 2005 Quantitative detection of the potato cyst nematode, Globodera pallida, and the beet cyst nematode, Heteroderas chachtii, using Real-Time PCR with SYBR green I dye. Mol. Cell Probe 19: 81-86.

Madani M, Ward L J \& De Boer S H 2011 Hsp90 gene, an additional target for discrimination between the potato cyst nematodes, Globodera rostochiensis and G. pallida, and the related species, G. tabacumtabacum. European J. Plant Pathol. 130: 271-285. 
Mokrini F, Waeyenberge L, Viaene N, Andaloussi F A \& Moens M 2013 Quantitative detection of the root-lesion nematode, Pratylenchus penetrans, using qPCR. European J. Plant Pathol. 137: 403-413.

Peng H, Peng D, Hu X, He X, Wang Q, Huang W \& He W 2012 Loop-mediated isothermal amplification for rapid and precise detection of the burrowing nematode, Radopholus similis, directly from diseased plant tissues. Nematol. 14: 977-986.

Reise R W, Huettel R N \& Sayre R M 1987 Carrot callus tissue for culture of endoparasitic nematodes. J. Nematol. 19: 387-389.

Sato E, Min Y Y, Shirakashi T, Wada S \& Toyota K 2007 Detection of the root-lesion nematode, Pratylenchus penetrans (Cobb), in a nematode community using real-time PCR. Japanese J. Nematol. 37: 87-92.

Sayler R J, Walker C, Goggin F, Agudelo P \& Kirkpatrick T 2012 Conventional PCR detection and real-time PCR quantification of reniform nematodes. Plant Dis. 96: 17571762.

Subbotin S A, Waeyenberge L \& Moens M 2000 Identification of cyst forming nematodes of the genus Heterodera (Nematoda: Heteroderidae) based on the ribosomal DNARFLP. Nematol. 2: 153-164.

Subbotin S A, Waeyenberge L, Molokanova I A \& Moens M 1999 Identification of Heterodera avenae group species by morphometrics and rDNA-RFLPs. Nematol. 1: 195-207.

Thorne G 1961 Principles of Nematology. McGrawHill, New York, USA, 553pp.

Toyota K, Shirakashi T, Sato E, Wada S \& Min Y Y 2008 Development of a real-time PCR method for the potato-cyst nematode Globodera rostochiensis and the root-knot nematode Meloidogyne incognita. Soil Sci. Plant Nutr. 54: 72-76.
Untergasser A, Nijveen H, Rao X, Bisseling T, Geurts R \& Leunissen J A 2007 Primer3Plus, an enhanced web interface to Primer3. Nucleic Acids Res. 35: W71-W74.

Van Ghelder C, Reid A, Kenyon D \& Esmenjaud D 2015 Development of a real-time PCR method for the detection of the dagger nematodes Xiphinema index, X. diversicaudatum, X. vuittenezi and $X$. italiae, and for the quantification of $X$. index numbers. Plant Pathol. 64: 489-500.

Vrain T C, Wakarchuk D A, Levesque A C \& Hamilton R I 1992 Intraspecific rDNA restriction fragment length polymorphism in the Xiphinema americanum group. Fund Appl. Nematol. 15: 563-573.

Wang M X, Zhu S F, Luo K, Zhou L H \& Zhao W J 2005 Studies on real- time fluorescent PCR with TaqMan probe for rDNA- ITS2 of pinewood nematode (Bursaphelenchus xylophilus). Sci. Silvae Sin 41: 82-85.

Wang Q, Geng L F, Zhang D S \& Peng D L 2011 Species specific molecular diagnosis of burrowing nematode (Radopholus similis). Acta Phys. Sin 41: 171-177.

Yan G P, Smiley R W \& Okubara P A 2012 Detection and quantification of Pratylenchus thornei in DNA extracted from soil using real-time PCR. Phytopathol. 102 :14-22.

Zijlstra C 2000 Identification of Meloidogyne chitwoodi, M. fallax and M. hapla based on SCAR-PCR: A powerful way of enabling reliable identification of populations or individuals that share common traits. European J. Plant Pathol. 106: 283-290.

Zijlstra C \& van Hoof R 2006 A multiplex real-time polymerase chain reaction (TaqMan) assay for the simultaneous detection of Meloidogyne chitwoodi and M. fallax. Phytopathol. 96: 12551262. 